\title{
Proton-detected MAS NMR experiments based on dipolar transfers for backbone assignment of highly deuterated proteins
}

\author{
Veniamin Chevelkov, Birgit Habenstein, Antoine Loquet ${ }^{1}$, Karin Giller, Stefan Becker, Adam Lange* \\ Max Planck Institute for Biophysical Chemistry, Department of NMR-based Structural Biology, Am Fassberg 11, 37077 Göttingen, Germany
}

\section{A R T I C L E I N F O}

\section{Article history}

Received 3 December 2013

Revised 19 February 2014

Available online 4 March 2014

\section{Keywords:}

Magic-angle spinning solid-state NMR

Deuteration

Proton detection

Protein resonance assignment

PrgI

Type 3 secretion system

\begin{abstract}
A B S T R A C T
Proton-detected solid-state NMR was applied to a highly deuterated insoluble, non-crystalline biological assembly, the Salmonella typhimurium type iii secretion system (T3SS) needle. Spectra of very high resolution and sensitivity were obtained at a low protonation level of $10-20 \%$ at exchangeable amide positions. We developed efficient experimental protocols for resonance assignment tailored for this system and the employed experimental conditions. Using exclusively dipolar-based interspin magnetization transfers, we recorded two sets of 3D spectra allowing for an almost complete backbone resonance assignment of the needle subunit Prgl. The additional information provided by the well-resolved proton dimension revealed the presence of two sets of resonances in the N-terminal helix of PrgI, while in previous studies employing ${ }^{13} \mathrm{C}$ detection only a single set of resonances was observed.
\end{abstract}

(c) 2014 Elsevier Inc. All rights reserved.

\section{Introduction}

Various sophisticated isotope labeling schemes, such as carbon selective labeling [1-3] and deuteration [4,5], facilitate the study of complex biomolecules by solid-state NMR (ssNMR). These approaches require, in turn, development and revision of existing protocols for an optimal performance. For complex protein investigations, protein perdeuteration with subsequent proton back-substitution on hydrogen exchangeable sites using a buffer containing a defined $\mathrm{H}_{2} \mathrm{O}-\mathrm{D}_{2} \mathrm{O}$ mixture is a very efficient approach to reduce the proton density and attenuate proton-proton dipolar couplings. For such protein systems, traditional ssNMR approaches, limited to the observation of ${ }^{13} \mathrm{C}$ and ${ }^{15} \mathrm{~N}$ nuclei, can be extended to proton detection [6,7], which provides better sensitivity compared to ${ }^{13} \mathrm{C}$ detection and improved resolution via the additional dimension. Even without high power proton decoupling, proton and nitrogen line widths in strongly deuterated proteins can be as sharp as $20 \mathrm{~Hz}$ and $12 \mathrm{~Hz}$, respectively [4,8]. Since no high power proton decoupling is required, long chemical shift evolution times can be used to obtain highly resolved multidimensional spectra. Relaxation studies on perdeuterated proteins provide unique information about dynamics in the solid state [9-11], which is not

\footnotetext{
* Corresponding author.

E-mail address: adla@nmr.mpibpc.mpg.de (A. Lange).

1 Institute of Chemistry \& Biology of Membranes \& Nanoobjects (UMR5248 CBMN), Institut Européen de Chimie et Biologie (IECB), CNRS - Universite Bordeaux - Institut Polytechnique Bordeaux, All. Geoffroy Saint-Hilaire, 33600 Pessac, France.
}

accessible in protonated samples at the same level of accuracy. High quality data has been obtained on longitudinal [12] and differential transverse relaxation [10,13] and order parameters $[10,14]$. These data can be used for an extended model-free relaxation analysis $[9,10]$. Furthermore, proton-proton distance measurements were performed in structural elucidations of several deuterated microcrystalline proteins [11,15-18].

The first essential step in structural NMR studies of proteins is the sequential assignment of the resonances. Even though deuterated proteins have only been studied for a relatively short time by solid-state NMR $[19,20]$, already a plethora of different methods for ${ }^{1} \mathrm{H},{ }^{13} \mathrm{C}$ and ${ }^{15} \mathrm{~N}$ assignment exists $[15,18,21-26]$. These approaches can be classified into two categories according to the protonation level and the accompanied typical experimental parameters: (1) fully protonated proteins [21,26,27] or perdeuterated proteins with complete reprotonation on exchangeable sites $[15,18]$, which require ultrafast MAS frequencies $(40-60 \mathrm{kHz})$ and very high external magnetic fields; (2) perdeuterated proteins with partial reprotonation on exchangeable sites (ca. 20-30\%) [22-25], which can be studied even at low external magnetic fields of 9.4 $\mathrm{T}$ and moderately high MAS rates between 20 and $32 \mathrm{kHz}$, achievable with $3.2 \mathrm{~mm}$ and $2.5 \mathrm{~mm}$ probe heads. The rotor size is an essential parameter in protein studies, since they are often limited by the sensitivity and require therefore the highest possible sample amount [28]. In general, the sensitivity and resolution of protondetected spectra are additionally depending on the MAS rate, protonation level, external magnetic field and the homogeneity of the investigated sample. 
All assignment approaches are based on the joined analysis of proton-detected triple resonance three dimensional (3D) experiments correlating $\mathrm{H}, \mathrm{N}, \mathrm{CA}, \mathrm{CO}$ and rarely $\mathrm{CB}$ atoms from residues $i$ and $i-1$. This allows for a "sequential walk" along the protein backbone resonances. In perdeuterated proteins with $100 \%$ re-protonation, $(\mathrm{H}) \mathrm{CANH}$ and $(\mathrm{H}) \mathrm{CONH} 3 \mathrm{D}$ spectra can be recorded using straightforward heteronuclear cross polarization transfer for each step, including the initial polarization of CA and CO $[15,18,21]$. $(\mathrm{H}) \mathrm{CA}(\mathrm{CO}) \mathrm{NH}$ and $(\mathrm{H}) \mathrm{CO}(\mathrm{CA}) \mathrm{NH}$ spectra require a specific $\mathrm{CA}-\mathrm{CO}$ magnetization transfer step, which can be achieved by pure through-bond INEPT transfer [18], utilizing the relatively high CA-CO scalar coupling or by through-space transfer based on DREAM [29] or HORROR [30] recoupling, optimized for one bond transfer [21]. The sensitivity of these experiments compared with $(\mathrm{H}) \mathrm{CANH}$ and $(\mathrm{H}) \mathrm{CONH}$ is determined by the efficiency of the CA-CO transfer which is around 20-60\%. In close analogy, similar approaches for $\mathrm{CA}-\mathrm{CB}$ magnetization transfer are used in $(\mathrm{H}) \mathrm{CB}(\mathrm{CA}) \mathrm{NH}$ or $(\mathrm{H}) \mathrm{CB}(\mathrm{CACO}) \mathrm{NH}$ experiments [21]. Solution state assignment approaches employing only scalar couplings are also applicable at ultrafast spinning and low reprotonation degree [10,31].

In partially reprotonated samples, $(\mathrm{H}) \mathrm{CANH}$ and $(\mathrm{H}) \mathrm{CONH}$ spectra can be readily recorded as in $100 \%$ reprotonated samples. Obtaining correlations between $\mathrm{CA}_{i-1}$ and $(\mathrm{HN})_{i}$, however, is a more challenging task, due to the low proton density, which limits the initial polarization of $\mathrm{CA}_{i-1}$. The magnetization transfer from $\mathrm{H}_{i-1}$ is reduced because of the low probability of proton occurrence, while the transfer from the weakly coupled $\mathrm{H}_{i}$ is inefficient due to the longer distance and dipolar truncation [32] caused by the strong dipolar coupling between $\mathrm{H}_{i}$ and $\mathrm{CA}_{i}$. The same issue affects correlations between $\mathrm{CO}_{i}$ and $(\mathrm{HN})_{i}$. At the same time, using a low reprotonation degree is a pre-requirement imposed by employing widely spread $3.2 \mathrm{~mm}$ and $2.5 \mathrm{~mm}$ probes with limited MAS rates. Thus, sequential resonance assignment of fractionally protonated samples at moderately high MAS rates $(<32 \mathrm{kHz})$ remains a considerable challenge. In the following we will briefly review the existing solutions.

Reif and coworkers implemented solution-like NMR approaches [22-24], utilizing only hetero- and homonuclear scalar couplings to obtain $\mathrm{H}_{i} \mathrm{~N}_{i} \mathrm{CO}_{i-1}, \mathrm{H}_{i} \mathrm{~N}_{i}-\mathrm{CA}_{i} / \mathrm{CA}_{i-1}, \mathrm{H}_{i} \mathrm{~N}_{i} \mathrm{CO}_{i-1} \mathrm{CA}_{i-1}, \mathrm{H}_{i} \mathrm{~N}_{i}-\mathrm{CA}_{i} \mathrm{CO}_{i} /$ $\mathrm{CA}_{i-1} \mathrm{CO}_{i-1}$ and $\mathrm{H}_{i} \mathrm{~N}_{i}-\mathrm{CA}_{i} \mathrm{CB}_{i} / \mathrm{CA}_{i-1} \mathrm{CB}_{i-1}$ correlations, providing extensive inter-residual connectivities for the small perdeuterated microcrystalline protein $\alpha$-SH3 with fractional proton back-substitution. Outstanding sharp lines, extremely low transverse relaxation rates, increased by elevated temperatures of $25-30{ }^{\circ} \mathrm{C}$ during the experiments and exploiting paramagnetic relaxation enhancement (PRE) shortening longitudinal relaxation times by a factor of 5-8 [33], facilitated the applicability of this approach. One drawback of this methodology is that the nitrogens with relatively short transverse relaxation times are simultaneously coupled to two CAs, from the same and the previous residue, via small scalar couplings. This results in split transfers and reduced spectral resolution due to the presence of both ${ }^{15} \mathrm{~N}-{ }^{13} \mathrm{CA}_{i} /{ }^{13} \mathrm{CA}_{i-1}$ correlations. While this approach yielded excellent results for $\alpha-\mathrm{SH} 3$, it may be difficult to apply to other samples with broader lines and faster transverse magnetization decays [34]. Linser [25] has recently suggested to use long range proton carbon cross polarization in order to correlate $(\mathrm{HN})_{i}$ with $\mathrm{CA}_{i-1}, \mathrm{CO}_{i}$, or $\mathrm{CB}_{i-1}$. The experimental schemes, namely hCxhNH, hCAhNH and hCOhNH were tested on a Cu(Edta) doped sample of $\alpha$-SH3 and provided valuable information for resonance assignment. However, dipolar truncation effects [32] arising from strong $\mathrm{H}_{i}$ and $\mathrm{CA}_{i} / \mathrm{CO}_{i-1}$ couplings may significantly suppress through-space magnetization transfer between $\mathrm{H}_{i}$ and $\mathrm{CA}_{i-1} / \mathrm{CO}_{i}$ in both directions.

Another assignment approach introduced by Ladizhansky and co-workers [35] is based on correlations of $\mathrm{H}_{i} \mathrm{~N}_{i}$ with $\mathrm{CA}_{i}, \mathrm{CO}_{i-1}$ and double quantum (DQ) coherences of $\mathrm{CO}_{i-1}-\mathrm{CA}_{i-1}, \mathrm{CA}_{i}-\mathrm{CO}_{i}$ and $\mathrm{CA}_{i}-\mathrm{CB}_{i}$ spins. To create DQ coherences, the SPC-5 sequence is used [36], which employs RF field strength 5 times higher than the MAS frequency, which may pose a restriction to the employed experimental conditions.

The achieved success of the deuteration approach in combination with proton detection motivated us to apply it to an insoluble, non-crystalline biological assembly, the Salmonella typhimurium type III secretion system (T3SS) needle [37]. The 80 residue subunit PrgI was perdeuterated and uniformly ${ }^{13} \mathrm{C},{ }^{15} \mathrm{~N}$ labeled with subsequent $10 \%$ or $20 \%$ proton back-substitution at exchangeable sites using a buffer containing a corresponding $\mathrm{H}_{2} \mathrm{O} / \mathrm{D}_{2} \mathrm{O}$ mixture. In the present work, we have developed two efficient experimental approaches for backbone assignment of such a fractionally reprotonated system at very fast MAS $(25-28 \mathrm{kHz})$ and moderate external magnetic field (600 MHz ${ }^{1} \mathrm{H}$ Larmor frequency), making use of the high sensitivity and resolution due to proton detection as well as the high efficiency of dipolar-based inter-nuclear magnetization transfer. The first introduced method exploits "out-andback" ${ }^{13} \mathrm{CA}-{ }^{13} \mathrm{CO}$ dipolar based magnetization transfer optimized specifically for directly bonded nuclei, yielding high sensitivity and resolution spectra with unambiguous information about inter-spin connectivity. The second approach employs long range $\mathrm{H}-\mathrm{CO}$ and $\mathrm{H}-\mathrm{CA}$ magnetization transfers to obtain high sensitivity spectra for backbone sequential assignment.

\section{Materials and methods}

\subsection{Sample preparation}

Expression, purification and polymerization of perdeuterated ${ }^{15} \mathrm{~N}$ - and ${ }^{13} \mathrm{C}$-labeled wild-type PrgI protein was performed as described before $[3,38,39]$. A low protonation degree in the samples was achieved according to the approach described earlier by Reif and coworkers [4]. Two samples were prepared using buffers with a fraction of either $10 \%$ or $20 \% \mathrm{H}_{2} \mathrm{O}$. Approximately $12 \mathrm{mg}$ of the $10 \% \mathrm{H}_{2} \mathrm{O}$ sample were packed into a $3.2 \mathrm{~mm}$ rotor. Approximately $25 \mathrm{mg}$ and $10 \mathrm{mg}$ of the $20 \% \mathrm{H}_{2} \mathrm{O}$ sample were packed into $3.2 \mathrm{~mm}$ and $2.5 \mathrm{~mm}$ rotors, respectively.

\subsection{Solid-state NMR spectroscopy}

Solid-state NMR experiments were conducted on $850 \mathrm{MHz}$, $800 \mathrm{MHz}$ and $600 \mathrm{MHz}\left({ }^{1} \mathrm{H}\right.$ Larmor frequency) spectrometers (Bruker Biospin, Germany) equipped with $\left({ }^{1} \mathrm{H},{ }^{13} \mathrm{C},{ }^{15} \mathrm{~N}\right)$ triple-resonance $2.5 \mathrm{~mm}(600 \mathrm{MHz})$ or $3.2 \mathrm{~mm}(800,850 \mathrm{MHz})$ probes. Samples were spun at rates of $25-28 \mathrm{kHz}(2.5 \mathrm{~mm}$ probe) or $20 \mathrm{kHz}$ (3.2 mm probes). The effective sample temperature was $11 \pm 2{ }^{\circ} \mathrm{C}$ as measured by the temperature-dependent water proton resonance relative to an internal DSS reference [40]. Chemical shift referencing was achieved using also the internal DSS reference.

The presented experiments are based on proton detection and the constant time approach, as introduced by Zilm and co-workers [20] for optimization of residual water proton signal suppression. Magnetization transfer steps between different nuclei were achieved by recoupling of hetero- or homo-nuclear dipolar interactions. For this purpose common recoupling techniques such as cross polarization (CP) [41], SPECIFIC-CP [42], HORROR or DREAM $[29,30]$ and band-selective homonuclear CP (BSH-CP) [38] were used. Details about RF field strengths and shaped pulses are listed in Table S1 (Supporting Information) for each experiment. For homonuclear double-quantum transfer, continuous ${ }^{13} \mathrm{C}$ RF irradiation was applied in the middle of the CA band, while the CO magnetization was aligned with a trim pulse along the effective RF field defined by chemical shift offset and RF field strength. No 
high-power proton decoupling was applied during chemical shift evolution periods and polarization transfer steps between low $\gamma$ nuclei. Gaussian pulse cascades [43] were used for band-selective $180^{\circ}$ pulses on CO or CA. Suppression of the remaining solvent proton magnetization was achieved by a proton pulse train comprising high and low power pulses, as explained in detail in Fig. S2, B (Supporting Information). Heteronuclear $J$ decoupling was applied during all chemical evolution periods. Homonuclear CO-CA scalar couplings were always removed during $\mathrm{CO}$ indirect chemical shift evolution times, while in some experiments they were not removed during CA indirect chemical shift evolution, as specified below. The results reported here were obtained on a $600 \mathrm{MHz}$ spectrometer and at an MAS rate of $28 \mathrm{kHz}$ or $25 \mathrm{kHz}$ using the sample with the $20 \%$ reprotonation level unless stated otherwise. All NMR spectra were analyzed using CCPNMR [44]. More experimental details are provided in the Supporting Information.

\section{Experimental results and discussion}

\subsection{High-resolution proton-detected spectra of deuterated PrgI needles}

The spectral quality essentially determines the success of NMR studies. Therefore, we examined resolution and sensitivity as a function of reprotonation level, MAS rate and external magnetic field. First, we recorded heteronuclear correlation spectra at an MAS rate of $20 \mathrm{kHz}$ for the sample with $10 \%$ reprotonation level on $800 \mathrm{MHz}$ and $850 \mathrm{MHz}$ spectrometers. For the sample with $20 \%$ reprotonation level we acquired spectra on the $800 \mathrm{MHz}$ spectrometer at $20 \mathrm{kHz}$ MAS and on the $600 \mathrm{MHz}$ spectrometer using an MAS rate of $28 \mathrm{kHz}$. Fig. 1 shows proton-detected $(\mathrm{H}) \mathrm{NH}$ and
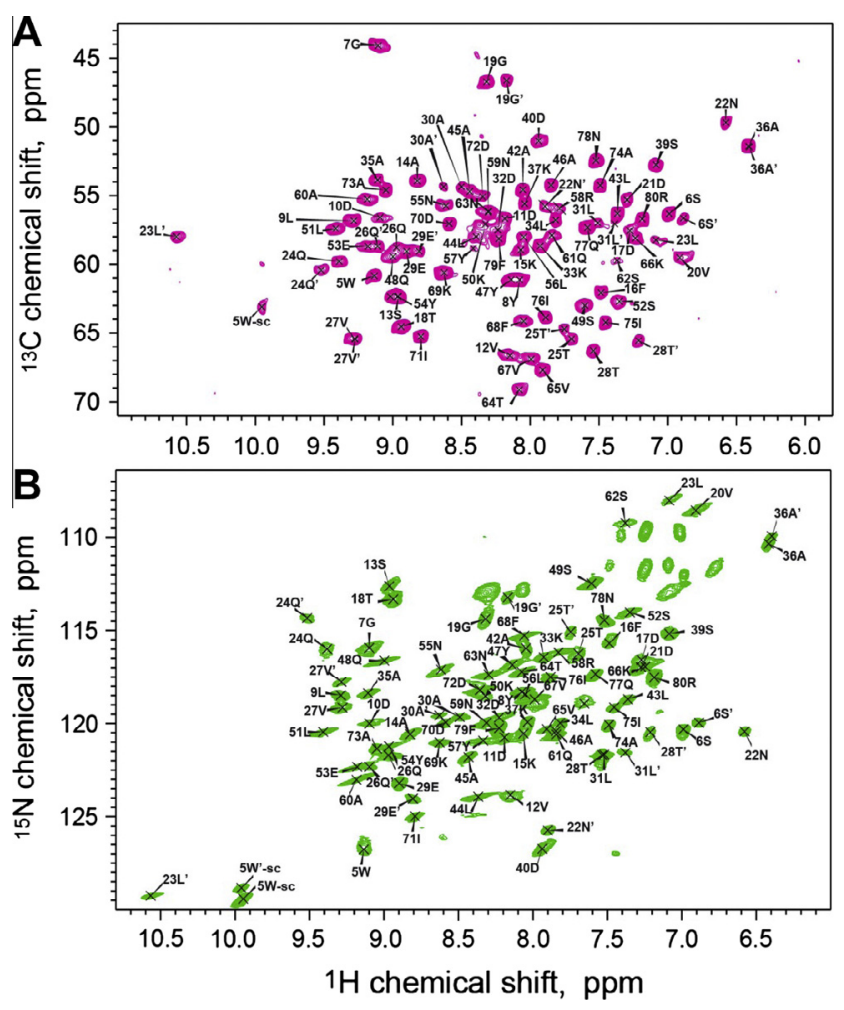

Fig. 1. Two-dimensional proton-detected $(\mathrm{HN}) \mathrm{CA}(\mathrm{N}) \mathrm{H}$ (panel $\mathrm{A}$ ) and $(\mathrm{H}) \mathrm{NH}$ (panel B) correlation spectra of deuterated PrgI T3SS needles. The spectra were obtained on a $600 \mathrm{MHz}$ spectrometer at an MAS rate of $28 \mathrm{kHz}$. The needles were perdeuterated and back protonated at amide sites at a level of $20 \%$. The prime sign refers to signals from a second polymorph.
$(\mathrm{HN}) \mathrm{CA}(\mathrm{N}) \mathrm{H}$ 2D heteronuclear correlation spectra obtained on the $600 \mathrm{MHz}$ spectrometer. The average proton and nitrogen line widths are $47 \mathrm{~Hz}$ and $16 \mathrm{~Hz}$, respectively. These values are larger than the ones obtained for microcrystalline $\alpha$-SH3, but close to results for a number of other systems [10,15,18,21,34], although a direct comparison is not possible due to significant variations of the experimental conditions. The line width dependence on the protonation level at different magnetic fields is summarized in Table 1. We found significant line width differences along the backbone, which might be a consequence of variations in local dynamics, structural heterogeneity, chemical exchange and other parameters. Longitudinal and transverse relaxation rates of bulk magnetization, obtained at different experimental conditions are given in Table S2 (Supporting Information). The system exhibits relatively long $\mathrm{T}_{2}$ times for ${ }^{1} \mathrm{H}$ and ${ }^{15} \mathrm{~N}$ which is reflected in high spectral resolution. The average differential line broadening [45] of ${ }^{15} \mathrm{~N}$ was around $10 \mathrm{~Hz}$, as determined for 16 well-resolved residues in the HN 2D spectrum recorded on the $850 \mathrm{MHz}$ spectrometer at an MAS rate of $20 \mathrm{kHz}$ without $\mathrm{HN} J$ decoupling in the ${ }^{15} \mathrm{~N}$ dimension. This value is close to previously reported ones for microcrystalline samples $[10,13]$, and does not advocate TROSY-type techniques [23,46,47] for mild resolution improvement at the cost of significant sensitivity losses. We found that increasing the reprotonation level from $10 \%$ to $20 \%$ leads to only slightly broader lines, while providing significantly higher sensitivity because of the increased amount of protons and considerable shortening of ${ }^{1} \mathrm{H}$ longitudinal relaxation. Similar results have been observed previously on a microcrystalline sample [8]. We also found that the HN spectra obtained using a higher MAS rate $(28 \mathrm{kHz})$ at lower external magnetic field $(600 \mathrm{MHz})$ show similar resolution and sensitivity compared to slower sample spinning $(20 \mathrm{kHz})$ at higher magnetic fields $(800 /$ $850 \mathrm{MHz}$ ). We therefore decided to perform all 3D experiments for assignment purposes at $28 \mathrm{kHz}$ MAS on the $600 \mathrm{MHz}$ spectrometer employing the sample with $20 \%$ reprotonation level.

\subsection{Design of 3D pulse sequences based on CA-CO "out-and-back" transfer for backbone resonance assignment}

As mentioned above, assignment experiments successfully employed previously for proteins with $100 \%$ reprotonation level are well applicable to obtain $\mathrm{H}_{i} \mathrm{~N}_{i} \mathrm{CA}_{i}$ and $\mathrm{H}_{i} \mathrm{~N}_{i} \mathrm{CO}_{i-1}$ correlations in biomolecules with low proton content, as used in the present work, but might not be efficient to obtain $\mathrm{H}_{i} \mathrm{~N}_{i} \mathrm{CA}_{i-1}$, and $\mathrm{H}_{i} \mathrm{~N}_{i} \mathrm{CO}_{i}$ correlations. However, the sensitivity of the latter experiments is a major determinant of the overall performance of a resonance assignment method. In order to establish inter-residue connectivity along the protein backbone, we designed here a set of protondetected 3D correlation experiments, optimized for proteins with low proton content on exchangeable sites and providing high sensitivity and resolution spectra with unambiguous interspin connectivity. The pulse sequences are based on an "out-and-back" concept and propagate initial magnetization of $\mathrm{H}_{i}$ to remote $\mathrm{CA}_{i-1}$ or $\mathrm{CO}_{i}$ spins and then back to $\mathrm{H}_{i}$ for detection. Only recoupled dipolar interactions are utilized for interspin magnetization transfers, optimized for specific transfer between directly bonded nuclei. These design concepts provide unambiguous information about inter-residual spin connectivity, high sensitivity and better resolution compared to other methods presented so far for highly deuterated proteins. An MAS frequency of $28 \mathrm{kHz}$ was employed for these experiments.

3D $\mathrm{H}_{i} \mathrm{~N}_{i} \mathrm{CA}_{i-1}, \mathrm{H}_{i} \mathrm{CO}_{i-1} \mathrm{CA}_{i-1}$ and $\mathrm{H}_{i} \mathrm{CA}_{i} \mathrm{CO}_{i}$ correlations were obtained by means of $(\mathrm{HCO}) \mathrm{CA}(\mathrm{CO}) \mathrm{NH},(\mathrm{H}) \mathrm{COCA}(\mathrm{CON}) \mathrm{H}$ and $(\mathrm{H}) \mathrm{CA}-$ $\mathrm{CO}(\mathrm{CAN}) \mathrm{H}$ pulse sequences, respectively. For example, in the ( $\mathrm{H}) \mathrm{COCA}(\mathrm{CON}) \mathrm{H}$ experiment, depicted in Fig. 2, initial magnetization of $\mathrm{H}_{i}$ was directly transferred to $\mathrm{CO}_{i-1}$ and further delivered to $\mathrm{CA}_{i-1}$ by HORROR/DREAM recoupling with $60 \%$ efficiency of 
Table 1

Average proton and nitrogen line widths (full width at half-maximum, FWHM) in spectra obtained under different experimental conditions.

\begin{tabular}{|c|c|c|c|c|c|}
\hline${ }^{1} \mathrm{H}, \%$ & $B_{0}, \mathrm{MHz}$ & $\omega_{r}, \mathrm{kHz}$ & ${ }^{1} \mathrm{H}$ FWHM, Hz & ${ }^{15} \mathrm{~N}$ FWHM, Hz & $\mathrm{H}-\mathrm{N} J$ decoupling on ${ }^{1} \mathrm{H}$ channel \\
\hline 10 & 800 & 20 & $58.4 \pm 21.2$ & $19.2 \pm 7.5$ & Single hard $180^{\circ}$ \\
\hline 20 & 800 & 20 & $63.9 \pm 21.0$ & $22.9 \pm 8.4$ & Single hard $180^{\circ}$ \\
\hline 20 & 600 & 28 & $47.0 \pm 14.0$ & $18.8 \pm 8.7$ & Single hard $180^{\circ}$ \\
\hline 20 & 600 & 28 & & $16.3 \pm 8.7$ & WALTZ-64 \\
\hline
\end{tabular}

(H) $\mathrm{COCA}(\mathrm{CON}) \mathrm{H}$

${ }^{1} \mathrm{H}$ water

saturation

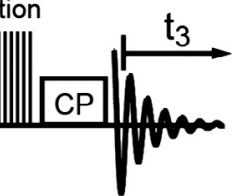

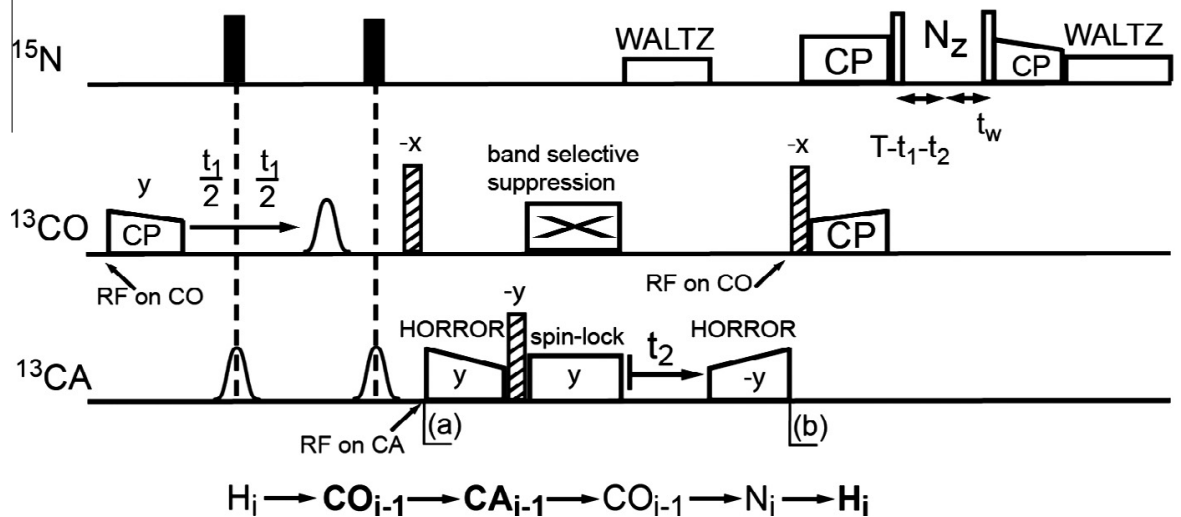

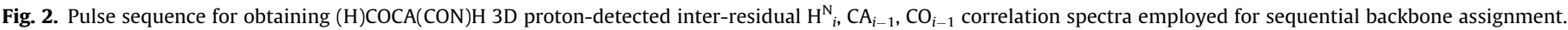

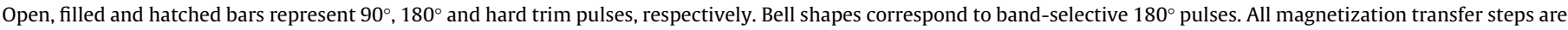

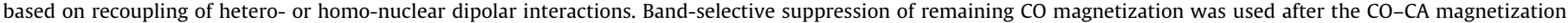

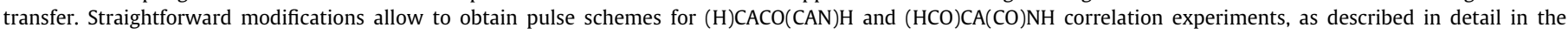
Supporting Information. The coherence transfer steps are schematically indicated at the bottom of the figure and observed nuclei are represented in bold.

the latter step. This concept is more efficient compared to direct $\mathrm{CP}$ from protons to $\mathrm{CA}_{i-1}$, because magnetization transfer from the $(i-1)$ hydrogen is very small due to the low probability of simultaneous proton occurrence at $\mathrm{H}_{i}$ and $\mathrm{H}_{i-1}$ in a $20 \%$ reprotonated sample. The direct transfer from the weakly coupled $\mathrm{H}_{i}$ is dipolar truncated [32] because of the stronger dipolar coupling between $\mathrm{H}_{i}$ and $\mathrm{CA}_{i}$. For back polarization transfer from $\mathrm{CA}_{i-1}$ to $\mathrm{H}_{i}$ we used 3 consecutive one-bond transfer steps, which unambiguously correlate $\mathrm{CA}_{i-1}, \mathrm{CO}_{i-1}, \mathrm{~N}_{i}$ and $\mathrm{H}_{i}$. In the presented experiment (Fig. 2), $\mathrm{NC}$ scalar couplings were removed by $180^{\circ}{ }^{15} \mathrm{~N}$ hard pulses during the CO chemical shift evolution, while carbon band-selective $180^{\circ}$ pulses [43] were used to remove the CO-CA J couplings. After the chemical shift evolution, the CO magnetization was flipped by a $65^{\circ}$ hard trim pulse along the effective RF field determined by the ${ }^{13} \mathrm{C}$ RF field applied on CA for HORROR/DREAM recoupling. After CO-CA transfer, the remaining CO magnetization was suppressed by band-selective recoupling achieved by a $21.5 \mathrm{kHz}$ spin lock field applied on CA, which results in an effective RF field of $28 \mathrm{kHz}$ (i.e. equal to the MAS rate) acting on CO. A more detailed description of "out" CO-CA and "back" CA-CO transfers with band-selective magnetization suppression (fragment between points a and b in Fig. 2) is shown in the Supporting Information (Fig. S5). The overall efficiency of the CO-CA-CO module was 33\%. During CA chemical shift evolution, NC $J$ couplings were removed by WALTZ-16 [48], but no CO-CA J decoupling was applied. "Back" CA-CO magnetization transfer was achieved by DREAM/ HORROR recoupling under continuous RF irradiation applied in the middle of the CA band. By means of a $65^{\circ}$ hard trim pulse, the $\mathrm{CO}$ magnetization was then flipped to the transverse plane for subsequent CO-N SPECIFIC CP [42]. The ${ }^{15} \mathrm{~N}$ magnetization was preserved along the $Z$ axis during suppression of the remaining water proton magnetization by a proton pulse train $[49,50]$, as shown in detail in Fig. S2 B (Supporting Information). The intensity of the first FID was $9.5 \%$ compared with the signal in an $(\mathrm{H}) \mathrm{NH}$ experiment. The $\mathrm{H}_{i} \mathrm{CO}_{i-1} \mathrm{CA}_{i-1}$ correlation spectrum was recorded with excellent resolution and sensitivity within a short time of $42 \mathrm{~h}$, using 16 scans, a $2.5 \mathrm{~s}$ inter-scan delay, and maximum isotropic chemical shift evolution times of $45 \mathrm{~ms}, 5.72 \mathrm{~ms}$ and $17.4 \mathrm{~ms}$ for ${ }^{1} \mathrm{H}, \mathrm{CA}$ and $\mathrm{CO}$, respectively.

The same approach can be readily applied to correlate $\mathrm{H}_{i}$ and $\mathrm{CO}_{i}$ nuclei. The straightforward modifications of the scheme described above for $(\mathrm{HCO}) \mathrm{CA}(\mathrm{CO}) \mathrm{NH}$ and $(\mathrm{H}) \mathrm{CACO}(\mathrm{CAN}) \mathrm{H}$ experiments, as used in the present study, are explained in detail in Fig. S4 and Table S3 (Supporting Information). In general, the transfer efficiency between low $\gamma$ nuclei was around $45-60 \%$ due to the long polarization life times in deuterated proteins. The high transfer efficiency resulted in spectra with high sensitivity even in $(\mathrm{HCO}) \mathrm{CA}(\mathrm{CO}) \mathrm{NH},(\mathrm{H}) \mathrm{COCA}(\mathrm{CON}) \mathrm{H}$ and $(\mathrm{H}) \mathrm{CACO}(\mathrm{CAN}) \mathrm{H}$ experiments, accommodating 5 transfer steps. The sensitivity of each experiment relative to $(\mathrm{H}) \mathrm{NH}$ was between $7.5 \%$ and $9.5 \%$ (see Table S3, Supporting Information), which is quite high for such complex ssNMR correlation experiments. As a result, the required measurement time was only 42-61 h for a single 3D experiment. In the recorded spectra, each amide proton or amide group correlates only to one CA and/or CO nucleus, yielding twice higher resolution compared to solution-like [24] or dipolar-based methods [25] reported previously for proton-diluted proteins. We found that $\mathrm{H}_{i} \mathrm{CO}_{i-1} \mathrm{CA}_{i-1}$ and $\mathrm{H}_{i} \mathrm{CA}_{i} \mathrm{CO}_{i}$ correlations are preferable to 
$\mathrm{H}_{i} \mathrm{~N}_{i} \mathrm{CA}_{i-1}$ and $\mathrm{H}_{i} \mathrm{~N}_{i} \mathrm{CO}_{i}$ correlations in order to establish $\mathrm{H}_{i}$ connectivity with $\mathrm{CA}_{i-1}$ and $\mathrm{CO}_{i}$, because of the higher resolution of $\mathrm{H}_{i} \mathrm{CO}_{i-1}$ and $\mathrm{H}_{i} \mathrm{CA}_{i}$ spectra compared to $\mathrm{H}_{i} \mathrm{~N}_{i}$ spectra. A set of four 3D $(\mathrm{H}) \mathrm{CANH},(\mathrm{H}) \mathrm{CONH},(\mathrm{H}) \mathrm{COCA}(\mathrm{CON}) \mathrm{H}$ and (H)CACO(CAN)H experiments yields the necessary information for the backbone resonance assignment using the frequencies of $\mathrm{CO}$ and $\mathrm{CA}$ nuclei to establish the connectivity between subsequent residues. An additional fifth 3D ( $\mathrm{HCO}) \mathrm{CA}(\mathrm{CO}) \mathrm{NH}$ experiment was recorded to compare the results with the $(\mathrm{H}) \mathrm{COCA}(\mathrm{CON}) \mathrm{H}$ spectrum.

We note that the proposed methodology can be performed as well if band-selective homonuclear (BSH) [38] CP is used instead of HORROR/DREAM for CO-CA magnetization transfer, as required in case of higher external magnetic field used with a $3.2 \mathrm{~mm}$ probe providing slower MAS rates. As an example a $(\mathrm{HCO}) \mathrm{CA}_{i-1}(\mathrm{CON}) \mathrm{H}_{i}$ 2D correlation spectrum obtained on the $800 \mathrm{MHz}$ spectrometer at $20 \mathrm{kHz}$ MAS is presented in Fig. S7.

Fig. 3 illustrates a sequential walk along the backbone between residues A73 and V65, based on the set of five 3D spectra. The resonance assignment strategy is based on keeping two frequencies per assignment step constant while adding one new frequency. Interspin connectivity between $\mathrm{H}_{i}, \mathrm{~N}_{i}, \mathrm{CA}_{i}$ and $\mathrm{CO}_{i-1}$ is established by $\mathrm{H}_{i} \mathrm{~N}_{i} \mathrm{CA}_{i}$ and $\mathrm{H}_{i} \mathrm{~N}_{i} \mathrm{CO}_{i-1}$ experiments. The $\mathrm{H}_{i} \mathrm{~N}_{i} \mathrm{CA}_{i-1}$ and $\mathrm{H}_{i} \mathrm{CO}_{i-1} \mathrm{CA}_{i-1}$ spectra provide both the $\mathrm{CA}_{i-1}$ frequency. They are therefore not both mandatory to obtain a complete set of sequential assignment experiments, but they mutually corroborate the assignment information of each other. The $\mathrm{H}_{i-1} \mathrm{CA}_{i-1} \mathrm{CO}_{i-1}$ spectrum provides the $\mathrm{H}_{i-1}$ frequency and the $\mathrm{H}_{i} \mathrm{~N}_{i} \mathrm{CA}_{i}$ spectrum yields the $\mathrm{N}_{i-1}$ frequency. The high quality of the set of five 3D spectra allowed for the unambiguous and reliable assignment of all ${ }^{1} \mathrm{H},{ }^{13} \mathrm{CA},{ }^{13} \mathrm{CO}$ and ${ }^{15} \mathrm{~N}$ backbone resonances (Table S4, Supporting Information; BMRB Entry: 18276; contains also stereospecifically assigned methyl resonances of Val and Leu [51]), except of ${ }^{15} \mathrm{~N}$ of the three prolines and all nuclei of the first 4 amino acids, because of their flexibility [52] and a proline in the 4th position. We found, that residues $6,19,22-31$ and 36 exhibit two independent sets of signals. The doubling is mostly restricted to the ${ }^{1} \mathrm{H}$ dimension, which explains why the second polymorph was not detected before in protonated samples where the sSNMR spectra were based exclusively on the observation of ${ }^{15} \mathrm{~N}$ and ${ }^{13} \mathrm{C}$ [39]. We found only slight chemical shift differences between earlier studied protonated [39] samples and the currently studied deuterated sample, which are completely explainable by the deuterium isotope effect [53]. The ${ }^{13} \mathrm{CA}$ and ${ }^{15} \mathrm{~N}$ resonances were up-field shifted on average by $0.31 \mathrm{ppm}$ and $0.29 \mathrm{ppm}$, respectively.
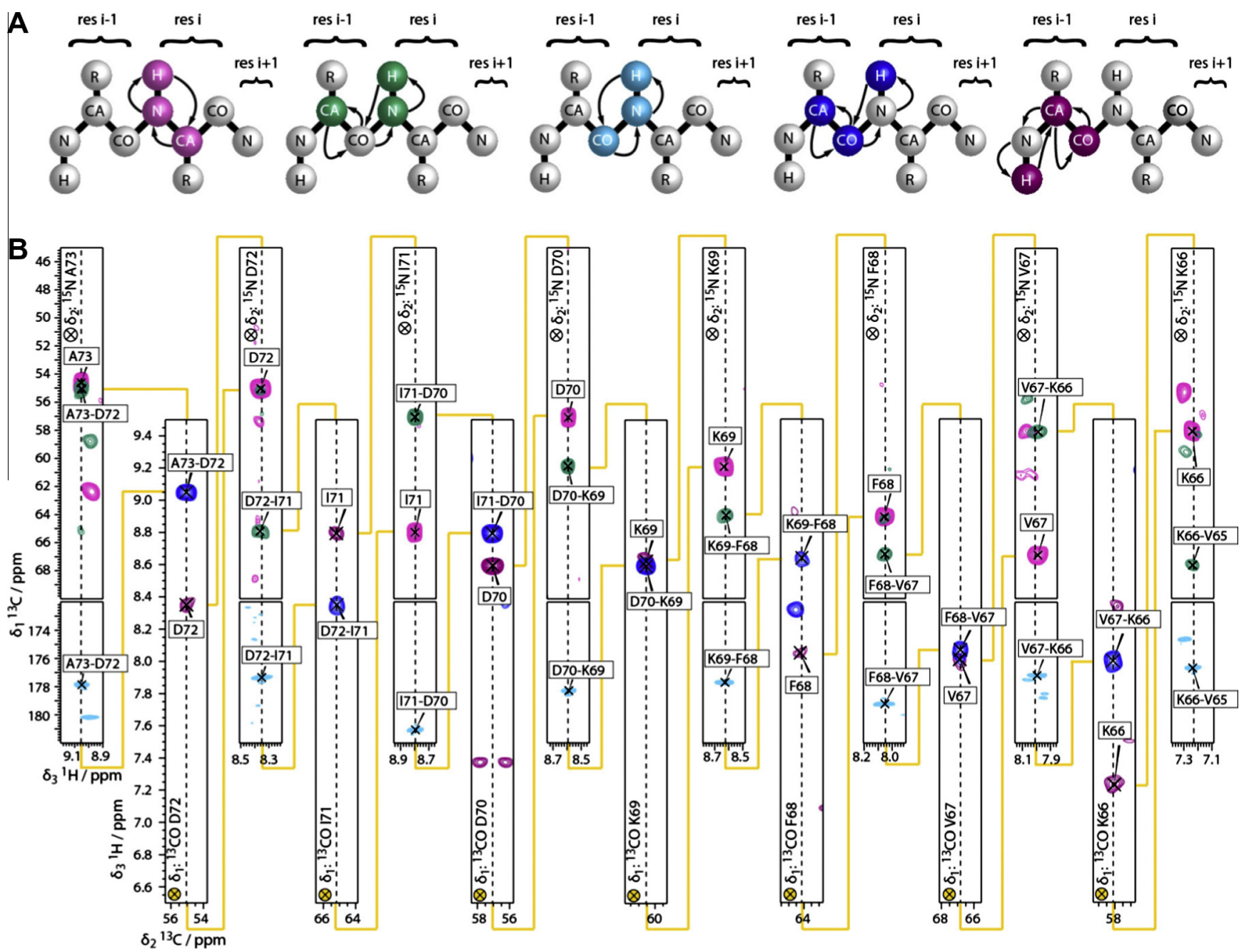

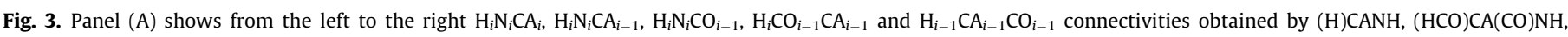

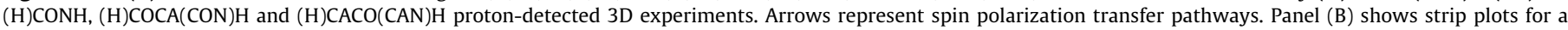

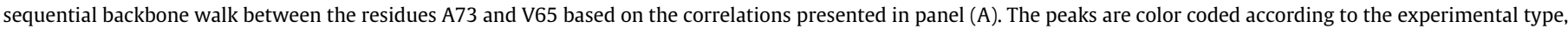

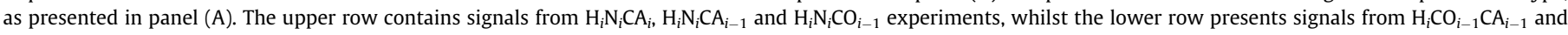

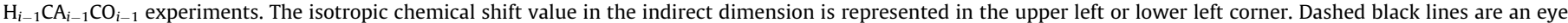

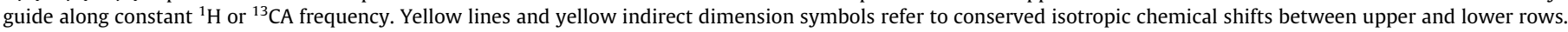
(For interpretation of the references to colour in this figure legend, the reader is referred to the web version of this article.) 
3.3. Design of 3D pulse sequences for backbone resonance assignment using long range $\mathrm{H}-\mathrm{C}$ dipolar transfers

In this section we demonstrate an efficient approach for backbone sequential assignment based on long range $\mathrm{H}_{i}-\mathrm{CA}_{i-1}$ and $\mathrm{H}_{i}-\mathrm{CO}_{i}$ cross polarization transfer. The $(\mathrm{H}) \mathrm{COCAH}$ pulse sequence and main magnetization transfer pathways achieved during this experiment are presented in Fig. 4. Initial proton magnetization was directly transferred to $\mathrm{CO}$ and after chemical shift evolution further distributed to CA by HORROR/DREAM recoupling (or at higher field and lower MAS rate: with BSH-CP) with $60 \%$ efficiency of the latter step. After subsequent isotropic chemical shift evolution, ${ }^{13} \mathrm{CA}$ magnetization was preserved along the $\mathrm{Z}$ axis for

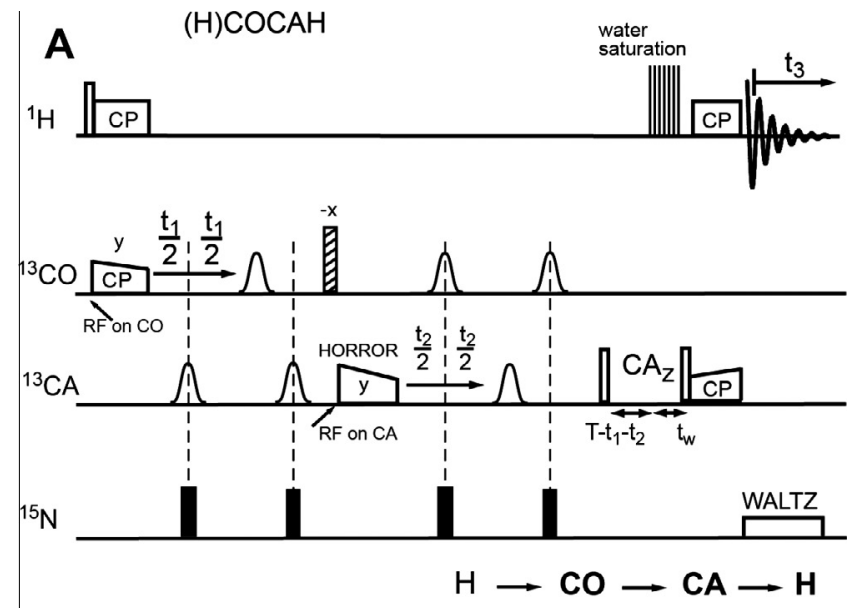

B

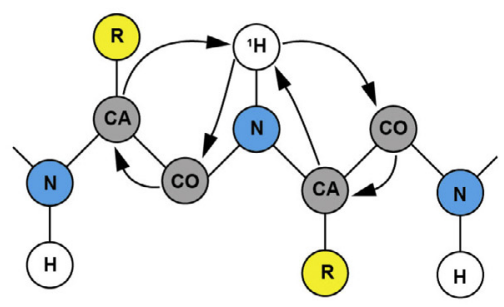

C

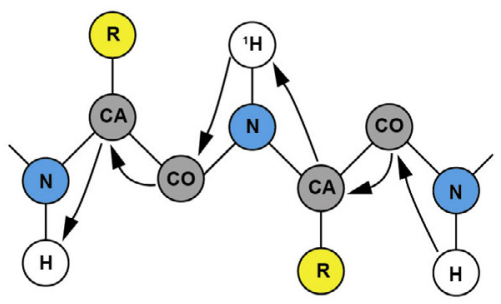

D

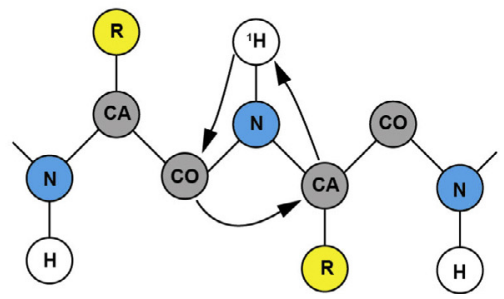

Fig. 4. Panel (A) shows the pulse sequence for the $3 \mathrm{D}(\mathrm{H}) \mathrm{COCAH}$ experiment for obtaining $\mathrm{H}^{\mathrm{N}}{ }_{i} \mathrm{CA}_{i-1} \mathrm{CO}_{i-1}$ and $\mathrm{H}^{\mathrm{N}}{ }_{i} \mathrm{CA}_{i} \mathrm{CO}_{i}$ correlations employed for sequential backbone assignment. Open, filled and hatched bars represent $90^{\circ}, 180^{\circ}$ and hard trim pulses, respectively. Bell shapes correspond to band-selective $180^{\circ}$ pulses. All magnetization transfer steps are based on recoupling of hetero- or homo-nuclear dipolar interactions. The general coherence transfer scheme is schematically indicated at the bottom of the panel (A) while panels (B)-(D) show the most probable site specific magnetization transfer pathways. suppression of the remaining water proton magnetization by a proton pulse train $[49,50]$, as shown in detail in Fig. S2 B (Supporting Information). For back polarization transfer from CA to $\mathrm{H}$ we used direct cross polarization. This approach provides $\mathrm{H}^{\mathrm{N}}{ }_{i} \mathrm{CO}_{i-1} \mathrm{CA}_{i-1}$ and $\mathrm{H}_{i}^{\mathrm{N}} \mathrm{CO}_{i} \mathrm{CA}_{i}$ correlations within a single spectrum, as it is visualized in Fig. 4. Panel $\mathrm{B}$ shows the most probable magnetization transfer pathways, while panel $C$ represents possible magnetization transfers if adjacent amide hydrogen positions are occupied by protons. If we assume that $\mathrm{H}_{i}-\mathrm{CA}_{i-1}$ and $\mathrm{H}_{i}-\mathrm{CO}_{i}$ as well $\mathrm{H}_{i}-\mathrm{CA}_{i}$ and $\mathrm{H}_{i}-\mathrm{CO}_{i-1}$ transfer efficiency are pairwise equal, then the intraresidual $\mathrm{H}_{i} \mathrm{CA}_{i} \mathrm{CO}_{i}$, correlations are expected to be more intense than the $\mathrm{H}_{i} \mathrm{CA}_{i-1} \mathrm{CO}_{i-1}$ correlations. We found that several residues exhibit $\mathrm{H}^{\mathrm{N}}{ }_{i} \mathrm{CO}_{i-1} \mathrm{CA}_{i}$ correlations as well (see Fig. 4D), despite the expected efficient truncation of magnetization transfer between $\mathrm{CO}_{i-1}$ and $\mathrm{CA}_{i}$ due to the strong $\mathrm{CO}_{i-1}$ and $\mathrm{CA}_{i-1}$ dipolar coupling. One explanation is the relatively low MAS rate of $25 \mathrm{kHz}$, which results in a relatively weak ${ }^{13} \mathrm{C} \mathrm{RF}$ field of ca. $6 \mathrm{kHz}$. At this condition, isotropic chemical shift variations can significantly affect effective RF field and the efficiency of homonuclear dipolar recoupling. In case of unfavorable isotropic chemical shift values, recoupling between $\mathrm{CO}_{i-1}$ and $\mathrm{CA}_{i-1}$ might be not optimal, and thus the truncation of magnetization transfer between $\mathrm{CO}_{i-1}$ and $\mathrm{CA}_{i}$ nuclei can be partially canceled. Higher MAS frequencies require stronger ${ }^{13} \mathrm{C}$ RF fields to fulfill the HORROR condition, thus the above described mechanism for magnetization transfer between $\mathrm{CO}_{i-1}$ and $\mathrm{CA}_{i}$ nuclei could be suppressed. To ensure long range magnetization transfer between $\mathrm{H}_{i}-\mathrm{CA}_{i-1}$ and $\mathrm{H}_{i}-\mathrm{CO}_{i}$ we employ relatively long contact times of $4.2-4.5 \mathrm{~ms}$, as optimized in a $1 \mathrm{D}$ version of the $(\mathrm{H}) \mathrm{COCAH}$ experiment. During $\mathrm{CO}$ and CA chemical shift evolution periods, NC scalar couplings were removed by $180^{\circ}{ }^{15} \mathrm{~N}$ hard pulses, while carbon band-selective $180^{\circ}$ pulses [43] were used to remove the CO-CA $J$ couplings. The intensity of the first FID was 20\% compared with the signal in an (H)NH experiment. The spectrum was recorded with excellent resolution and sensitivity within a short time of $64 \mathrm{~h}$, using 16 scans, a $2.5 \mathrm{~s}$ inter-scan delay, and maximum isotropic chemical shift evolution times of $45 \mathrm{~ms}, 22.7 \mathrm{~ms}$ and $7.0 \mathrm{~ms}$ for ${ }^{1} \mathrm{H}, \mathrm{CO}$ and $\mathrm{CA}$, respectively.

In the recorded spectrum, each amide proton correlates to two CA-CO couples yielding twice less resolution compared to the method introduced above. On the other hand this approach yields at least 1.5 times higher sensitivity for $\mathrm{H}^{\mathrm{N}} \mathrm{CO}_{i-1} \mathrm{CA}_{i-1}$ and $\mathrm{H}^{\mathrm{N}} \mathrm{CO}_{i-}$ $\mathrm{CA}_{i}$ correlations (see Table $\mathrm{S} 3$ ), despite the fact that it is based on truncated long-range ${ }^{1} \mathrm{H}-{ }^{13} \mathrm{CA} /{ }^{13} \mathrm{CO}$ transfer. The higher sensitivity of this method comparaed to the above discussed approach is due to fewer transfer steps and the fact that it contains both $\mathrm{H}_{i}-\mathrm{CA}_{i-1}$ and $\mathrm{H}_{i}-\mathrm{CO}_{i}$ correlations. Also the experiment is very straightforward to setup and implement. A set of three 3D (H)CANH, $(\mathrm{H}) \mathrm{CONH}$ and $(\mathrm{H}) \mathrm{CACOH}$ experiments provides the necessary information for the backbone resonance assignment using the frequencies of $\mathrm{CO}$ and $\mathrm{CA}$ nuclei to establish the connectivity between subsequent residues. During CA chemical shift evolution in the (H)CANH experiment, CA-CO $J$ couplings were removed by band selective $180^{\circ}$ pulses as plotted in Fig. S3. (H)CONH and (H)CACOH experiments were recorded within a short time of 26 and $18 \mathrm{~h}$, respectively.

A sequential walk along the backbone between residues Q48 and P41, based on the set of three 3D spectra is demonstrated by aligned strips in Fig. 5. If $\mathrm{CO}_{i-1}$ and $\mathrm{H}_{i}$ frequencies are known, the $\mathrm{H}^{\mathrm{N}}{ }_{i} \mathrm{CO}_{i-1} \mathrm{CA}_{i-1}$ and $\mathrm{H}^{\mathrm{N}}{ }_{i} \mathrm{CO}_{i} \mathrm{CA}_{i}$ correlations, represented in blue color, provide the $\mathrm{CA}_{i-1}$ and $\mathrm{H}_{i-1}$ frequency, respectively. $\mathrm{H}_{i} \mathrm{~N}_{i} \mathrm{CA}_{i}$ (green) and $\mathrm{H}_{i} \mathrm{~N}_{i} \mathrm{CO}_{i-1}$ (magenta) correlations establish the $\mathrm{N}_{i-1}$ and $\mathrm{CO}_{i-2}$ frequencies. The high quality of the spectra allowed for the unambiguous and reliable assignment of most ${ }^{1} \mathrm{H},{ }^{13} \mathrm{CA},{ }^{13} \mathrm{CO}$ and ${ }^{15} \mathrm{~N}$ backbone resonances, except of ${ }^{15} \mathrm{~N}$ of the three prolines, all nuclei of the first 4 amino acids, because of their flexibility [52] and a proline in the 4th position, residues 22 and 23, as well 


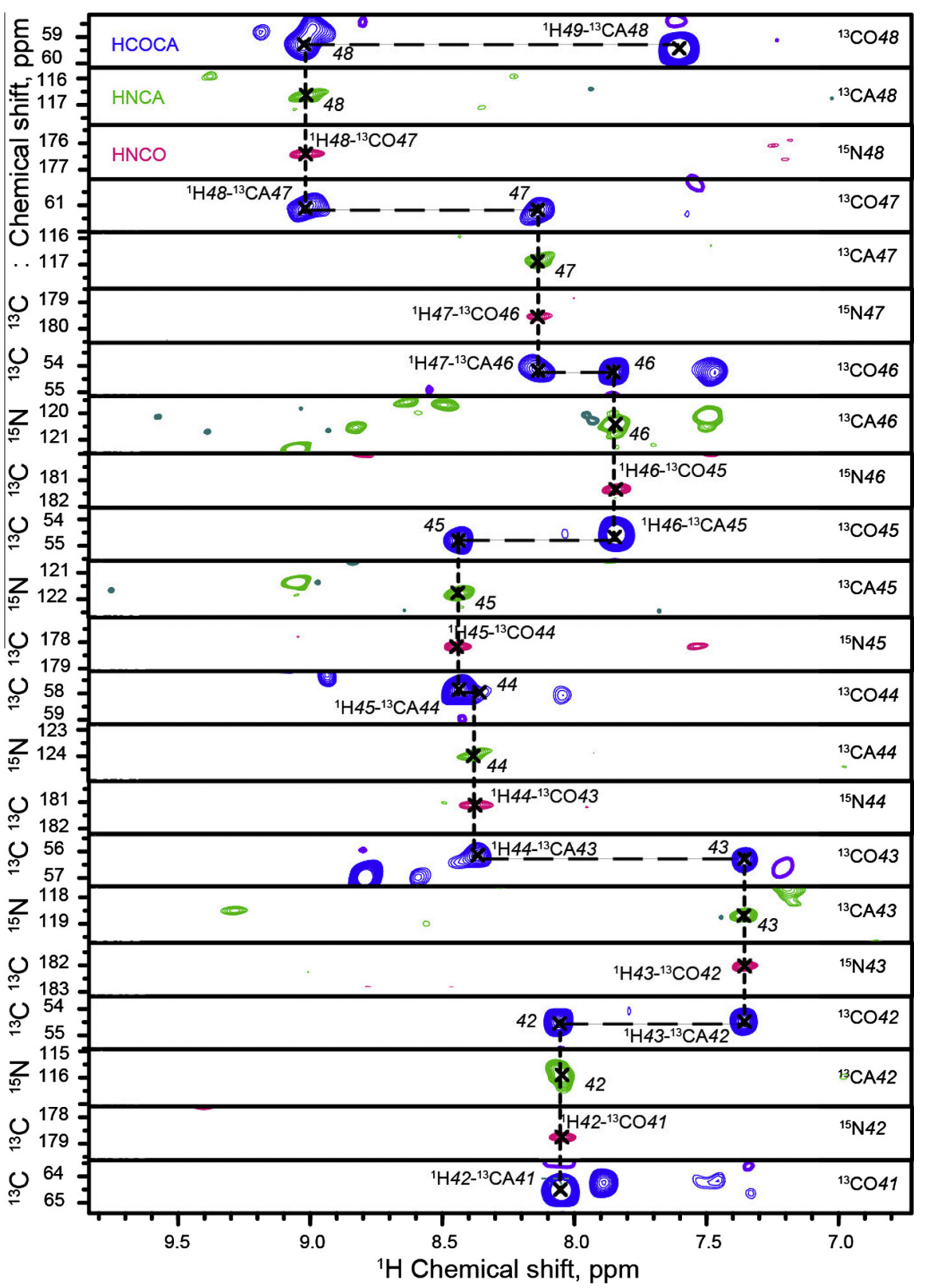

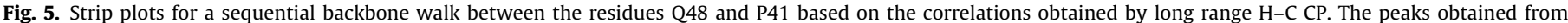

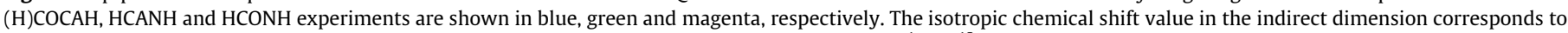

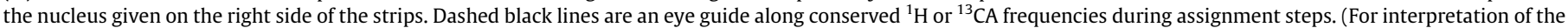
references to colour in this figure legend, the reader is referred to the web version of this article.)

residues 50 and 62 , whose signals were only observable in the direct $(\mathrm{H}) \mathrm{NH} 2 \mathrm{D}$ correlation spectrum during this second measurement session. We could confirm that residues $6,19,24-31$ and 36 exhibit two independent sets of signals.

\subsection{Efficiency of different experimental schemes}

Fig. 6 compares the efficiency of the above introduced HCACOCANH, HCOCACONH and HCOCAH experiments and presented earlier pulse sequences: (i) HCOCACONH based on out-and-back CO-CA INEPT transfer [54] and (ii) HCACONH and HCOCANH experiments employing DREAM for magnetization transfer between CO and CA spins [21]. All heteronuclear transfers in these pulse schemes were achieved by $\mathrm{CP}$. Detailed descriptions of the latter experiments are given elsewhere [21,54], their analysis is presented in the introduction and pulse sequences are depicted in the Supporting Information, Fig. S8. All data were obtained at an MAS rate of $25 \mathrm{kHz}$ and were recorded within the same experimental session. Number of scans, experiment type and efficiency relative to the $\mathrm{HNH}$ experiment are given in the panels. Essentially, the efficiency of all experiments is similar and a choice of the pulse sequence is then mostly determined by the protonation level and the transverse coherence decay time $T_{2}^{\prime}$ of ${ }^{13} \mathrm{CO}$.

Strong ${ }^{13} \mathrm{CO}-{ }^{13} \mathrm{CA} J$ couplings and a long ${ }^{13} \mathrm{C} \mathrm{T}_{2}^{\prime}$ suggest the use of INEPT for "out-and-back" (CO)CA(CO) steps [54]. Considering a CO transverse relaxation time of $25-40 \mathrm{~ms}$, the expected efficiency of the $(\mathrm{CO}) \mathrm{CA}(\mathrm{CO})$ block is $48-63 \%$ in case of ideal performance of the applied pulse train. However, non-negligible magnetization losses can occur due to RF field inhomogeneity, because the INEPT block comprises 6 pulses. In general, the efficiency of this method 


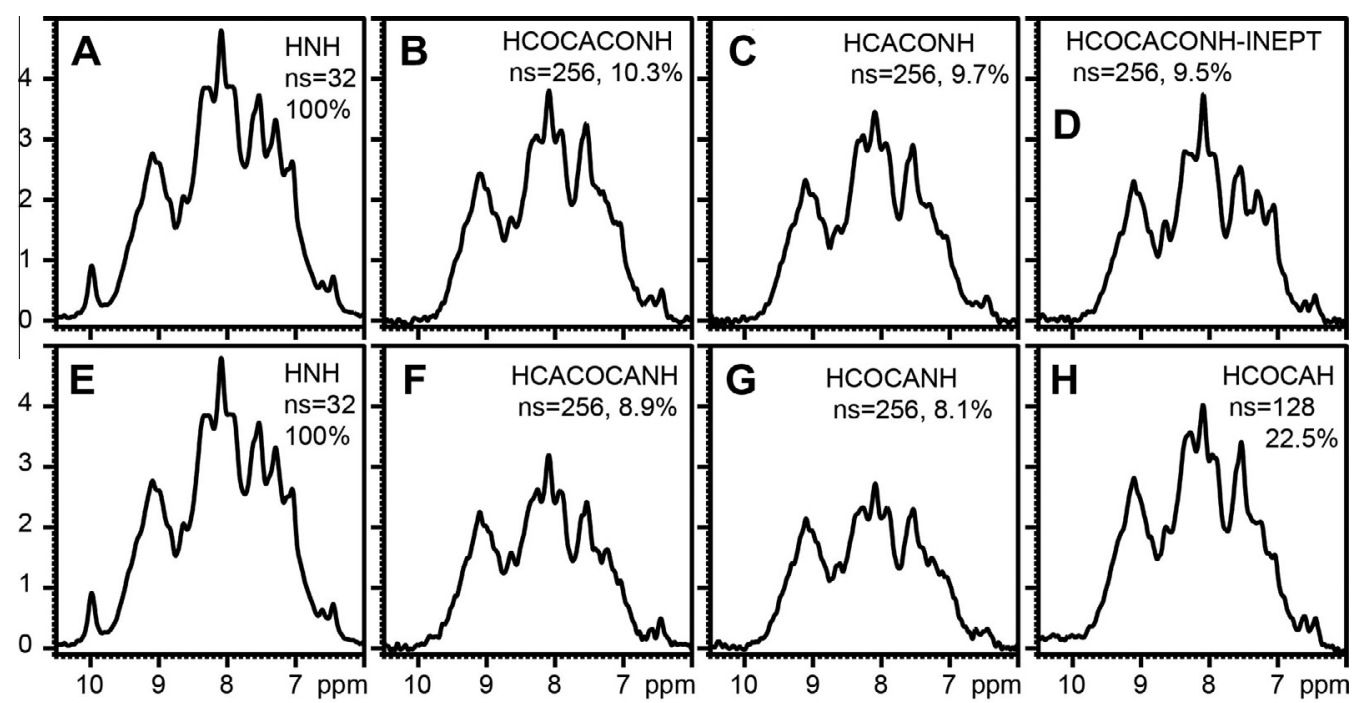

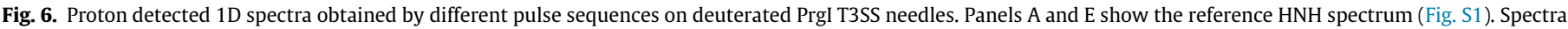

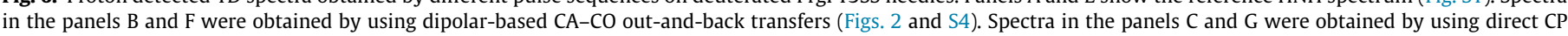

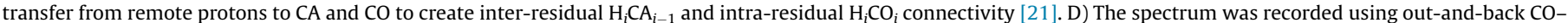

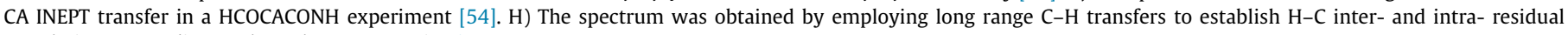
correlations, according to the pulse sequence in Fig. 4.

is strongly influenced by the transverse magnetization life time, which can be quite short for some biomolecules due to specific internal motions, low temperature and presence of paramagnetic centers for relaxation enhancement. Recently, Reif and co-workers found a $T_{2}^{\prime}$ of ${ }^{15} \mathrm{~N}$ for a number of systems within $10-15 \mathrm{~ms}$ [34], while $T_{2}^{\prime}$ of CO is typically shorter than of ${ }^{15} \mathrm{~N}$. For a CO transverse relaxation time of $10-15 \mathrm{~ms}$, the expected efficiency of the (CO)CA(CO) block drops to $18-31 \%$ in case of ideal performance of the applied pulse train, thus making scalar coupling based transfer between $\mathrm{CO}$ and CA less practical.

As it has been discussed above, initial polarization of $\mathrm{CA}_{i-1}$ in $\mathrm{H}_{i}-\mathrm{CA}_{i-1}$ correlation experiments using direct $\mathrm{CP}$ transfer from protons is not efficient in highly deuterated proteins, because of the low probability of $\mathrm{H}_{i-1}$ proton occurrence and because the transfer from the weakly coupled $\mathrm{H}_{i}$ is inefficient due to the longer distance and dipolar truncation [32] caused by the strong dipolar coupling between $\mathrm{H}_{i}$ and $\mathrm{CA}_{i}$. The presented results demonstrate that 2-step transfer comprising $\mathrm{H}_{i}-\mathrm{CO}_{i-1}$ and $\mathrm{CO}_{i-1}-\mathrm{CA}_{i-1}$ magnetization transfers is more preferable than direct magnetization transfer to $\mathrm{CA}_{i-1}$ from $\mathrm{H}_{i}$ and $\mathrm{H}_{i-1}$ at the here considered low protonation degree. At the same time the found efficiency of HCACONH and HCOCANH experiments was higher than expected with the used $20 \%$ reprotonation buffer. One possible explanation is that the real protonation degree might be higher, because water can be absorbed from the atmosphere during sample preparation.

\section{Conclusion}

We have demonstrated that the deuteration approach applied to PrgI needles yields proton-detected solid-state NMR spectra of high resolution and sensitivity. We then designed for proteins with extremely low proton content of $10-20 \%$ on exchangeable sites two efficient assignment approaches which employ proton detection and exclusively dipolar-based magnetization transfer steps. The method based on "out-and-back" ${ }^{13} \mathrm{CA}-{ }^{13} \mathrm{CO}$ magnetization transfers provides unambiguous information about inter-residual spin connectivity, high sensitivity and better resolution compared to other methods presented before, making this approach highly attractive for even more complex proteins. The approach utilizing long range ${ }^{1} \mathrm{H}-{ }^{13} \mathrm{CA}$ and ${ }^{1} \mathrm{H}-{ }^{13} \mathrm{CO}$ magnetization transfers yields higher sensitivity and is very simple to setup, making this approach highly useful as well. The excellent data quality allowed for an almost complete backbone resonance assignment of the 80-residue needle subunit PrgI employing a moderate external magnetic field of $14.1 \mathrm{~T}$ (600 MHz ${ }^{1} \mathrm{H}$ Larmor frequency) and an MAS rate of $25-28 \mathrm{kHz}$. All 3D spectra were recorded in a relatively short time frame (see Table S3), ranging from $18 \mathrm{~h}$ to $61 \mathrm{~h}$ for a single experiment. A previously unidentified second polymorph of the PrgI needles was assigned, due to the additional information granted by the proton dimension. All the doubled residues are close to W5 in the 3D structure [3] which may indicate that the line splitting is due to ring current effects caused by the side chain of W5. This would explain why protons are more affected than carbons. We will investigate this effect more carefully in future studies.

\section{Data deposition}

Chemical shifts are deposited in the BMRB (BMRB Entry: 18276)

\section{Acknowledgments}

We thank Brigitta Angerstein for expert technical assistance. This work was supported by the Max Planck Society and the DFG (Emmy Noether Fellowship to A.L.). B.H. acknowledges funding from EMBO (long-term fellowship).

\section{Appendix A. Supplementary material}

Supplementary data associated with this article can be found, in the online version, at http://dx.doi.org/10.1016/j.jmr.2014.02.020.

\section{References}

[1] M. Hong, K. Jakes, Selective and extensive C-13 labeling of a membrane protein for solid-state NMR investigations, J. Biomol. NMR 14 (1999) 71-74.

[2] F. Castellani, B.J.v. Rossum, A. Diehl, K. Rehbein, H. Oschkinat, Structure of a protein determined by solid-state magic-angle spinning NMR spectroscopy, Nature 420 (2002) 98-102. 
[3] A. Loquet, N.G. Sgourakis, R. Gupta, K. Giller, D. Riedel, C. Goosmann, C. Griesinger, M. Kolbe, D. Baker, S. Becker, A. Lange, Atomic model of the type III secretion system needle, Nature 486 (2012) 276-279.

[4] V. Chevelkov, K. Rehbein, A. Diehl, B. Reif, Ultrahigh resolution in proton solidstate NMR spectroscopy at high levels of deuteration, Angew. Chem. Int. Ed. 45 (2006) 3878-3881.

[5] B. Reif, Ultra-high resolution in MAS solid-state NMR of perdeuterated proteins: Implications for structure and dynamics, J. Magn. Reson. 216 (2012) 1-12.

[6] Y. Ishii, R. Tycko, Sensitivity enhancement in solid state N-15 NMR by indirect detection with high-speed magic angle spinning, J. Magn. Reson. 142 (2000) 199-204.

[7] Y. Ishii, J.P. Yesinowski, R. Tycko, Sensitivity enhancement in solid-state C-13 NMR of synthetic polymers and biopolymers by H-1 NMR detection with highspeed magic angle spinning, J. Am. Chem. Soc. 123 (2001) 2921-2922.

[8] U. Akbey, S. Lange, W.T. Franks, R. Linser, K. Rehbein, A. Diehl, B.J. van Rossum, B. Reif, H. Oschkinat, Optimum levels of exchangeable protons in perdeuterated proteins for proton detection in MAS solid-state NMR spectroscopy, J. Biomol. NMR 46 (2010) 67-73.

[9] V. Chevelkov, U. Fink, B. Reif, Quantitative analysis of backbone motion in proteins using MAS solid-state NMR spectroscopy, J. Biomol. NMR 45 (2009) 197-206.

[10] P. Schanda, B.H. Meier, M. Ernst, Quantitative analysis of protein backbone dynamics in microcrystalline ubiquitin by solid-state NMR spectroscopy, J. Am. Chem. Soc. 132 (2010) 15957-15967.

[11] M.J. Knight, A.J. Pell, I. Bertini, I.C. Felli, L. Gonnelli, R. Pierattelli, T. Herrmann, L. Emsley, G. Pintacuda, Structure and backbone dynamics of a microcrystalline metalloprotein by solid-state NMR, Proc. Nat. Acad. Sci. USA 109 (2012) 11095-11100.

[12] V. Chevelkov, A.V. Zhuravleva, Y. Xue, B. Reif, N.R. Skrynnikov, Combined analysis of $\mathrm{N}-15$ relaxation data from solid- and solution-state NMR Spectroscopy, J. Am. Chem. Soc. 129 (2007). 12594-+.

[13] V. Chevelkov, A. Diehl, B. Reif, Quantitative measurement of differential N-15$\mathrm{H}$-alpha/beta T-2 relaxation rates in a perdeuterated protein by MAS solidstate NMR spectroscopy, Magn. Reson. Chem. 45 (2007) S156-S160.

[14] V. Chevelkov, U. Fink, B. Reif, Accurate determination of order parameters from $\mathrm{H}-1, \mathrm{~N}-15$ dipolar couplings in MAS solid-state NMR experiments, J. Am. Chem. Soc. 131 (2009) 14018-14022.

[15] D.H. Zhou, J.J. Shea, A.J. Nieuwkoop, W.T. Franks, B.J. Wylie, C. Mullen, D. Sandoz, C.M. Rienstra, Solid-rate protein-structure determination with protondetected triple-resonance 3D magic-angle-spinning NMR spectroscopy, Angew. Chem. Int. Ed. 46 (2007) 8380-8383.

[16] M. Huber, S. Hiller, P. Schanda, M. Ernst, A. Bockmann, R. Verel, B.H. Meier, A proton-detected 4D solid-state NMR experiment for protein structure determination, ChemPhysChem 12 (2011) 915-918.

[17] R. Linser, B. Bardiaux, V. Higman, U. Fink, B. Reif, Structure calculation from unambiguous long-range amide and methyl (1) $\mathrm{H}-(1) \mathrm{H}$ distance restraints for a microcrystalline protein with MAS solid-state NMR spectroscopy, J. Am. Chem. Soc. 133 (2011) 5905-5912.

[18] M.J. Knight, A.L. Webber, A.J. Pell, P. Guerry, E. Barbet-Massin, I. Bertini, I.C. Felli, L. Gonnelli, R. Pierattelli, L. Emsley, A. Lesage, T. Herrmann, G. Pintacuda, Fast resonance assignment and fold determination of human superoxide dismutase by high-resolution proton-detected solid-state MAS NMR spectroscopy, Angew. Chem. Int. Ed. 50 (2011) 11697-11701.

[19] V. Chevelkov, B.J.v. Rossum, F. Castellani, K. Rehbein, A. Diehl, M. Hohwy, S. Steuernagel, F. Engelke, H. Oschkinat, B. Reif, H-1 detection in MAS solid-state NMR Spectroscopy of biomacromolecules employing pulsed field gradients for residual solvent suppression, J. Am. Chem. Soc. 125 (2003) 7788-7789.

[20] E.K. Paulson, C.R. Morcombe, V. Gaponenko, B. Dancheck, R.A. Byrd, K.W. Zilm, Sensitive high resolution inverse detection NMR spectroscopy of proteins in the solid state, J. Am. Chem. Soc. 125 (2003) 15831-15836.

[21] D.H. Zhou, A.J. Nieuwkoop, D.A. Berthold, G. Comellas, L.J. Sperling, M. Tang, G.J. Shah, E.J. Brea, L.R. Lemkau, C.M. Rienstra, Solid-state NMR analysis of membrane proteins and protein aggregates by proton detected spectroscopy, J. Biomol. NMR 54 (2012) 291-305.

[22] R. Linser, U. Fink, B. Reif, Narrow carbonyl resonances in proton-diluted proteins facilitate NMR assignments in the solid-state, J. Biomol. NMR 47 (2010) 1-6.

[23] R. Linser, U. Fink, B. Reif, Assignment of dynamic regions in biological solids enabled by spin-state selective NMR experiments, J. Am. Chem. Soc. 132 (2010). 8891-+.

[24] R. Linser, U. Fink, B. Reif, Proton-detected scalar coupling based assignment strategies in MAS solid-state NMR spectroscopy applied to perdeuterated proteins, J. Magn. Reson. 193 (2008) 89-93.

[25] R. Linser, Backbone assignment of perdeuterated proteins using long-range $\mathrm{H}$ / C-dipolar transfers, J. Biomol. NMR 52 (2012) 151-158.

[26] D.H. Zhou, G. Shah, M. Cormos, C. Mullen, D. Sandoz, C.M. Rienstra, Protondetected solid-state NMR Spectroscopy of fully protonated proteins at $40 \mathrm{kHz}$ magic-angle spinning, J. Am. Chem. Soc. 129 (2007) 11791-11801.

[27] A. Marchetti, S. Jehle, M. Felletti, M.J. Knight, Y. Wang, Z.Q. Xu, A.Y. Park, G. Otting, A. Lesage, L. Emsley, N.E. Dixon, G. Pintacuda, Backbone assignment of fully protonated solid proteins by $1 \mathrm{H}$ detection and ultrafast magic-anglespinning NMR spectroscopy, Angew. Chem. Int. Ed. 51 (2012) 10756-10759.

[28] J.-P. Demers, V. Chevelkov, A. Lange, Progress in correlation spectroscopy at ultra-fast magic-angle spinning: Basic building blocks and complex experiments for the study of protein structure and dynamics, Solid State Nucl. Magn. Reson. 40 (2011) 101-113.

[29] R. Verel, M. Ernst, B.H. Meier, Adiabatic dipolar recoupling in solid-state NMR the DREAM scheme, J. Magn. Reson. 150 (2001) 81-99.

[30] N.C. Nielsen, H. Bildsoe, H.J. Jakobsen, M.H. Levitt, Double-quantum homonuclear rotary resonance. Efficient dipolar recovery in magic-angle spinning nuclear magnetic resonance, J. Chem. Phys. 101 (1994) 1805-1812.

[31] P. Schanda, M. Huber, R. Verel, M. Ernst, B.H. Meier, Direct detection of $(3 \mathrm{~h}) \mathrm{J}\left(\mathrm{NC}^{\prime}\right)$ hydrogen-bond scalar couplings in proteins by solid-state NMR spectroscopy, Angew. Chem. Int. Ed. 48 (2009) 9322-9325.

[32] P. Hodgkinson, L. Emsley, The accuracy of distance measurements in solidstate NMR, J. Magn. Reson. 139 (1999) 46-59.

[33] R. Linser, V. Chevelkov, A. Diehl, B. Reif, Sensitivity enhancement using paramagnetic relaxation in MAS solid-state NMR of perdeuterated proteins, J. Magn. Reson. 189 (2007) 209-216.

[34] R. Linser, M. Dasari, M. Hiller, V. Higman, U. Fink, J.M.L. del Amo, S. Markovic, L. Handel, B. Kessler, P. Schmieder, D. Oesterhelt, H. Oschkinat, B. Reif, Protondetected solid-state NMR spectroscopy of fibrillar and membrane proteins, Angew. Chem. Int. Ed. 50 (2011) 4508-4512.

[35] M.E. Ward, L. Shi, E. Lake, S. Krishnamurthy, H. Hutchins, L.S. Brown, V. Ladizhansky, Proton-detected solid-state NMR reveals intramembrane polar networks in a seven-helical transmembrane protein proteorhodopsin, J. Am. Chem. Soc. 133 (2011) 17434-17443.

[36] M. Hohwy, C.M. Rienstra, C.P. Jaroniec, R.G. Griffin, Fivefold symmetric homonuclear dipolar recoupling in rotating solids: application to double quantum spectroscopy, J. Chem. Phys. 110 (1999) 7983-7992.

[37] G.R. Cornelis, H. Wolf-Watz, The Yersinia Yop virulon: a bacterial system for subverting eukaryotic cells, Mol. Microbiol. 23 (1997) 861-867.

38] V. Chevelkov, K. Giller, S. Becker, A. Lange, Efficient CO-CA transfer in highly deuterated proteins by band-selective homonuclear cross-polarization, J Magn. Reson. 230 (2013) 205-211.

[39] A. Loquet, G. Lv, K. Giller, S. Becker, A. Lange, C-13 Spin dilution for simplified and complete solid-state NMR resonance assignment of insoluble biologica assemblies, J. Am. Chem. Soc. 133 (2011) 4722-4725.

[40] A. Boeckmann, C. Gardiennet, R. Verel, A. Hunkeler, A. Loquet, G. Pintacuda, L. Emsley, B.H. Meier, A. Lesage, Characterization of different water pools in solid-state NMR protein samples, J. Biomol. NMR 45 (2009) 319-327.

[41] A. Pines, J.S. Waugh, M.G. Gibby, Proton-enhanced nuclear induction spectroscopy - method for high-resolution NMR of dilute spins in solids, J. Chem. Phys. 56 (1972). 1776-\&

[42] M. Baldus, A.T. Petkova, J. Herzfeld, R.G. Griffin, Cross polarization in the tilted frame: assignment and spectral simplification in heteronuclear spin systems, Mol. Phys. 95 (1998) 1197-1207.

[43] L. Emsley, G. Bodenhausen, Gaussian pulse cascades - new analytical functions for rectangular selective inversion and in-phase excitation in NMR, Chem. Phys. Lett. 165 (1990) 469-476.

[44] W.F. Vranken, W. Boucher, T.J. Stevens, R.H. Fogh, A. Pajon, P. Llinas, E.L. Ulrich, J.L. Markley, J. Ionides, E.D. Laue, The CCPN data model for NMR spectroscopy: development of a software pipeline, Proteins 59 (2005) 687-696.

[45] M. Goldman, Interference effects in the relaxation of a pair of unlike spin- $1 / 2$ nuclei, J. Magn. Reson. 60 (1984) 437-452.

[46] V. Chevelkov, K. Faelber, A. Schrey, K. Rehbein, A. Diehl, B. Reif, Differential line broadening in MAS solid-state NMR due to dynamic interference, J. Am. Chem. Soc. 129 (2007) 10195-10200.

[47] K. Pervushin, R. Riek, G. Wider, K. Wuthrich, Attenuated T-2 relaxation by mutual cancellation of dipole-dipole coupling and chemical shift anisotropy indicates an avenue to NMR structures of very large biological macromolecules in solution, Proc. Nat. Acad. Sci. USA 94 (1997) 12366-12371.

[48] A.J. Shaka, J. Keeler, T. Frenkiel, R. Freeman, An improved sequence for broadband decoupling - WALTZ-16, J. Magn. Reson. 52 (1983) 335-338.

[49] G. Otting, NMR studies of water bound to biological molecules, Prog. NMR Spect. 31 (1997) 259-285.

[50] D.H. Zhou, C.M. Rienstra, High-performance solvent suppression for proton detected solid-state NMR, J. Magn. Reson. 192 (2008) 167-172.

[51] G.H. Lv, H.K. Fasshuber, A. Loquet, J.P. Demers, V. Vijayan, K. Giller, S. Becker, A. Lange, A straightforward method for stereospecific assignment of val and leu prochiral methyl groups by solid-state NMR: scrambling in the 2-C-13 Glucose labeling scheme, J. Magn. Reson. 228 (2013) 45-49.

[52] A. Loquet, B. Habenstein, A. Lange, Structural investigations of molecular machines by solid-state NMR, Acc. Chem. Res. 46 (2013) 2070-2079.

[53] P.E. Hansen, Isotope effects in nuclear shielding, Prog. NMR Spect. 20 (1988) 207-255.

[54] E. Barbet-Massin, A.J. Pell, K. Jaudzems, W.T. Franks, J.S. Retel, S. Kotelovica, I. Akopjana, K. Tars, L. Emsley, H. Oschkinat, A. Lesage, G. Pintacuda, Out-andback $\mathrm{C}-13-\mathrm{C}-13$ scalar transfers in protein resonance assignment by protondetected solid-state NMR under ultra-fast MAS, J. Biomol. NMR 56 (2013) 379386. 